\title{
Mid-latitude noctilucent cloud observations by lidar
}

\author{
G. von Cossart, P. Hoffmann, U. von Zahn, \\ Institut fur Atmosphärenphysık an der Universität Rostock, Germany \\ P. Keckhut and A. Hauchecorne \\ Service d'Aeronomie du CNRS, Verrieres, France
}

\begin{abstract}
Regular zenith-directed Rayleigh lidar soundings at Juliusruh $\left(54.63^{\circ} \mathrm{N}, 13.38^{\circ} \mathrm{E}\right)$ in summer 1995 indicated the presence of overhead noctilucent clouds (NLC) during three nights in June. For two of these nights, NLC were also sighted visually near the northern horizon. For one of the lidar-observed NLC events, temperature profiles were obtained immediately prior to the appearance of the NLC. These show at $81 \mathrm{~km}$ a strong cooling of about $30 \mathrm{~K}$ within two hours. The wind velocity and direction during the NLC events were inferred from daytime common-volume MF radar wind measurements. During the occurrence of the NLCs the interpolated MF radar wind was south-westwards directed with velocities between $9-32 \mathrm{~m} / \mathrm{s}$. Different from high latitudes, NLCs can be observed by lidar at mid-latitudes in total darkness. Therefore, mid-latitude observations hold the promise to allow a characterisation of NLC particle size distributions and particle densities even with comparatively simple, multi-color lidars.
\end{abstract}

\section{Introduction}

Noctilucent clouds (NLC) were first identified as a distinct atmospheric phenomenon near the end of the nineteenth century by $O$. Jesse [1885]. This twilight phenomenon appears during the summertime at high to middle latitudes near $83 \mathrm{~km}$. Today it is generally assumed that NLC are formed by water ice particles. This hypothesis is supported by observations of temperatures in the range of $130-150 \mathrm{~K}$ in the polar summer mesosphere [von Zahn and Meyer, 1989; von Zahn, 1990]. In the past 110 years, NLCs were observed by a great variety of ground based methods, by rocket experiments, and from satellites. With the first successful NLC sounding by a ground based lidar by Hansen et al. [1989], a new active remote sensing approach was available for NLC studies. Since 1991 an increasing number of NLC observations by lidar has been reported from polar and high latitudes [Langer et al., 1995; Thayer and Nilsen, 1995; Lübken et al., 1996; Nussbaumer et al., 1996] and mid-latitudes [Thomas et al., 1994] as well. Long-term observations of the NLC frequency and brightness by lidar should allow to record climatic changes of the summer mesopause region at mid-latitudes. Visual observations at mid-latitudes of overhead NLC are rare so far. One example is Jesse [1890], who describes visual observations of $\mathrm{NLC}$ in the zenith above Berlin $\left(52.5^{\circ} \mathrm{N}, 13.2^{\circ} \mathrm{E}\right)$ during the summers from 1885 to 1887 . Here we report on lidar measurements of three NLC events during summer 1995 at mid-latitudes near $55^{\circ} \mathrm{N}$ in connection with simultaneous visual observations of NLCs near the northern horizon in two cases and with daytime common-volume MF radar wind measurements.

\section{Copyright 1996 by the American Geophysical Union.}

\section{Instruments and data analysis}

In November 1993 a Rayleigh lidar (nicknamed HERMES lidar) of the Service d'Aeronomie du CNRS was installed at the field station of the Institute of Atmospheric Physics (IAP) in Juliusruh $\left(54.63^{\circ} \mathrm{N}, 13.38^{\circ} \mathrm{E}\right)$, where it is operated by IAP staff. The zenith-directed lidar system samples the elastic backscatter from molecules and aerosols over the altitude range from 15 to $95 \mathrm{~km}$ at $75 \mathrm{~m}$ spatial resolution. From the elastic backscattering we can deduce the temperature and the backscatter ratio. The system consists of a Nd:YAG laser, transmitting at $532 \mathrm{~nm}$ with $500 \mathrm{~mJ}$ pulse energy at $30 \mathrm{~Hz}$ pulse repetition frequency, a receiving telescope with $0.8 \mathrm{~m}^{2}$ area, and a two-channel photon counter. The field of view of the telescope is set to $200 \mu \mathrm{rad}$ for the high altitude channel and to $400 \mu$ rad for the low altitude channel (for additional details, see Keckhut et al. [1993]).

Here we present the measured lidar backscatter signals after they have been corrected for background, range dependence, and counter saturation. For the description of aerosols we use the backscatter ratio $R(z)$. It is defined as the ratio of the total to the molecular backscatter signal

$$
R(z)=\frac{\text { total signal }(z)}{\text { molecular signal }(z)}=\frac{B_{M}(z)+B_{A}(z)}{B_{M}(z)}
$$

where $\mathrm{z}$ denotes the geometric altitude, $B$ the volume backscatter coefficient and the subscripts $A$ and $M$ refer to aerosols and molecules, respectively. Within the NLC layer, $B_{M}$ is deduced from air densities taken from the COSPAR International Reference Atmosphere CIRA 86.

The visual observations of NLCs were done at Arkona, $7.8 \mathrm{~km}$ due North of Juliusruh. The observers estimated (a) the time of occurrence, (b) the lowest and highest elevation of the NLC-illuminated area and (c) the azimuth relative to the North of the left and right edges of the illuminated area.

At the Juliusruh field station the IAP also operates a MF radar for wind observations at mesospheric and lower thermospheric heights using the FM-CW technique at $3.18 \mathrm{MHz}$ [Singer et al., 1992]. Applying the spaced antenna method mean wind values are available in height steps of $1.5 \mathrm{~km}$ with a time resolution of $30 \mathrm{~min}$. For our investigations, an 83-km-wind vector was derived from measurements of the altitude range $80-86 \mathrm{~km}$ for the zonal and meridional wind directions. Unfortunately, the MF radar wind measurements are limited to daytime conditions, which in June are typically between 04:30 and 19:00 UT. For a zero-order description of the dynamical situation during the (nighttime) NLC events, the wind results derived from the evening hours before and the morning hours after the NLC observations (12:00-19:00 UT and 04:30-12:00 UT, respectively) were jointly analysed: The wind measurements were decomposed mathematically into a steady wind plus a semidiurnal tide. The latter is the dominating tide at mesopause heights at mid-lati- 
Table 1. NLC Observations at Juliusruh in June 1995

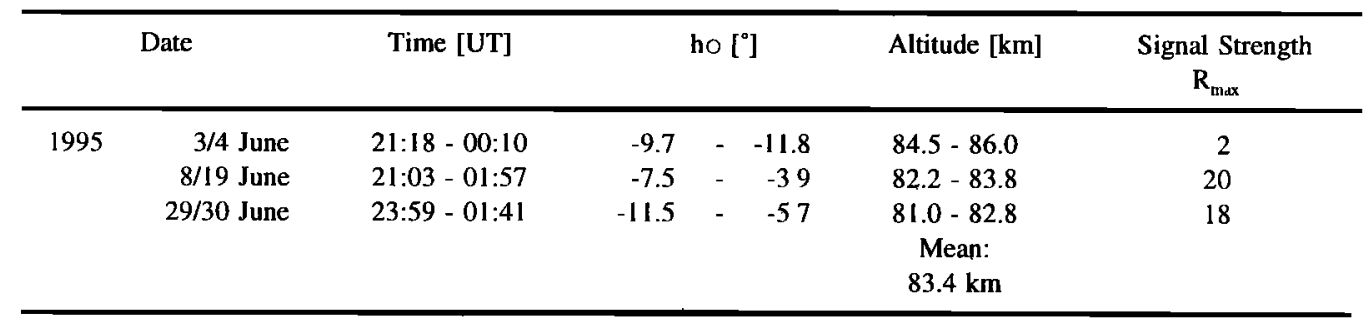

tudes. Th1s decomposition was used to estimate the wind during the periods of NLC observations.

\section{Observations}

In the period from May to August, 1995 we had 40 nights with lidar observations. Only during three nights in June, the 3rd, $18 \mathrm{th}$, and $29 \mathrm{th}$, were enhanced backscatter signals recorded from the altitude range $81-86 \mathrm{~km}$. These enhanced backscatter signals are caused by NLCs overhead at Juliusruh. Table 1 quantifies the characteristics of the detected NLCs: The first column gives the date of observation; the second column gives the time period of the occurrence of NLCs in UT time and the third the sun elevation (negative below the horizon); the fourth column indicates the altitude range of the aerosol layers; the fifth column quantifies the NLC signal strengths by giving the peak backscatter ratio Rmax. Figure 1 shows the backscatter ratio, $\mathrm{R}$, versus altitude for the three NLC events. The integration periods for the three R-profiles are 172, 294, and 102 minutes. The dotted lines in the Figure 1 are the $1-\sigma$-statistical noise levels assuming a Poisson distribution for the counts. During the NLC observations, solar elevation angles ranged from $-7.5^{\circ}$ to $-3.9^{\circ}$. The maximum backscatter ratio, obtained from integration over the entire NLC period, ranges from 2 to 20. For the events of June 03/04 and $18 / 19$ the integration period is identical with the total period of measurements. However, for June 29/30 the observation period is longer than the NLC event.

NLC above Juliusruh in June 1995

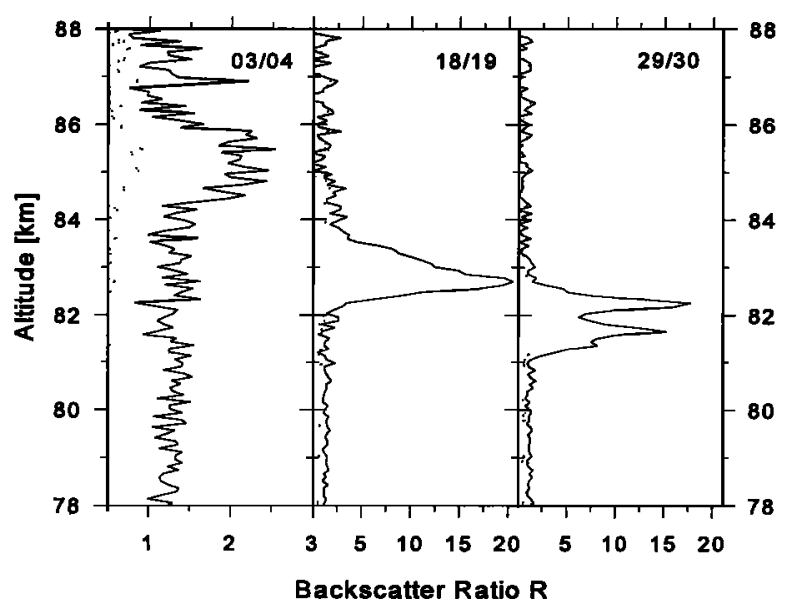

Figure 1. Backscatter ratios versus altitude for the three NLC events observed at Juliusruh $\left(54.63^{\circ} \mathrm{N} ; 13.38^{\circ} \mathrm{E}\right)$ in June 1995. Integration periods for the three profiles are 172, 294, and 102 $\min$, respectively. The dotted lines are the $1-\sigma$-statistical noise levels.
Figure 2 depicts the temporal evolution of the NLC layers on June $18 / 19$ and $29 / 30$. The contours denote levels of constant backscatter ratio with $R=3,6,9,12,15,18$. On June $18 / 19$ the aerosol layer maintains an almost constant altitude throughout the observation period. The start of the lidar measurements, at 21:18 UT, coincides with the strongest part of the NLC. Afterwards the signal strength decreases until the end of measurements. The NLC of June $29 / 30$ shows a distinct double layer structure. This NLC was recognized at 23:59 UT by the lidar. The contour plot shows two maxima: the first around 01:00 UT at $81.6 \mathrm{~km}$ and after that a second at $82.2 \mathrm{~km}$.

In the case of the June 29/30 NLC it was possible to derive temperature profiles from the Rayleigh backscatter just before the

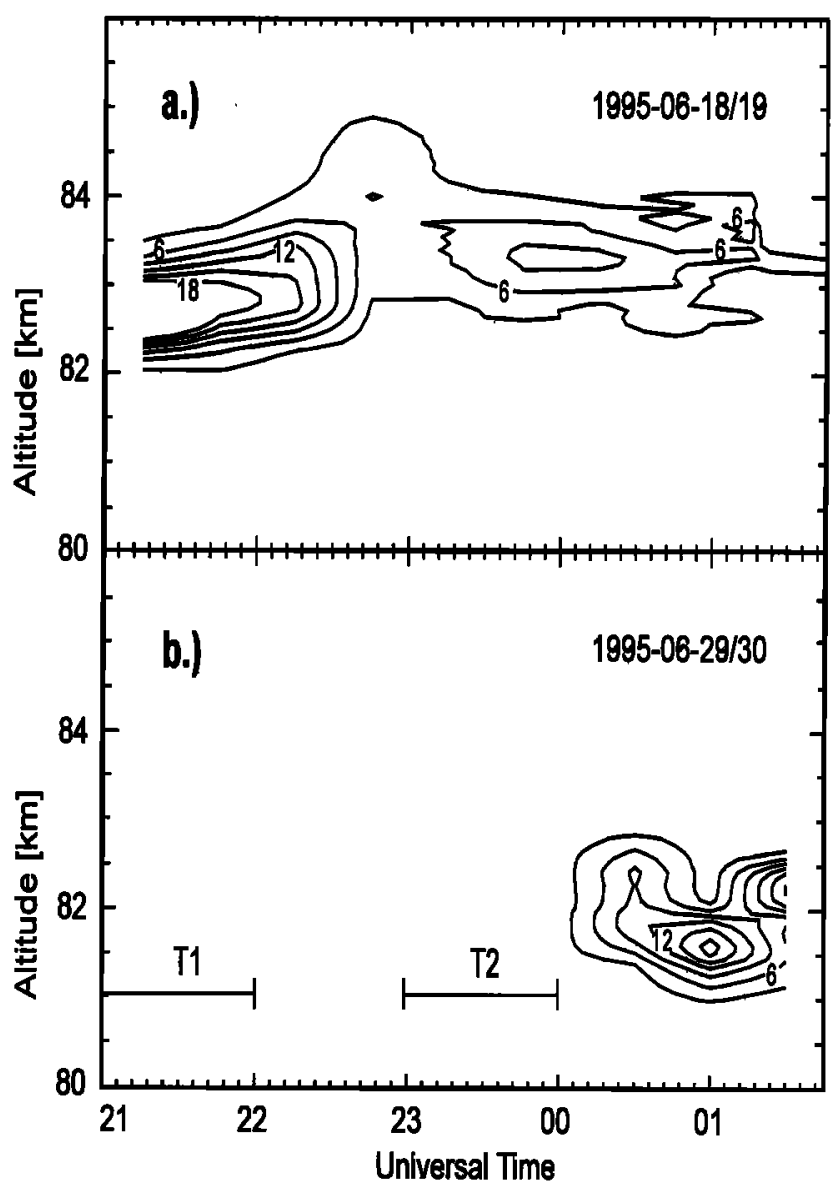

Figure 2. Contour plots of the backscatter ratio $R$, versus time and altitude for the NLC events of June 18/19 (panel a) and June 29/30, 1995 (panel b). Bars T1 and T2 mark the time periods of temperature determination. The contour lines represent levels with $R=3,6,9,12,15,18$. 


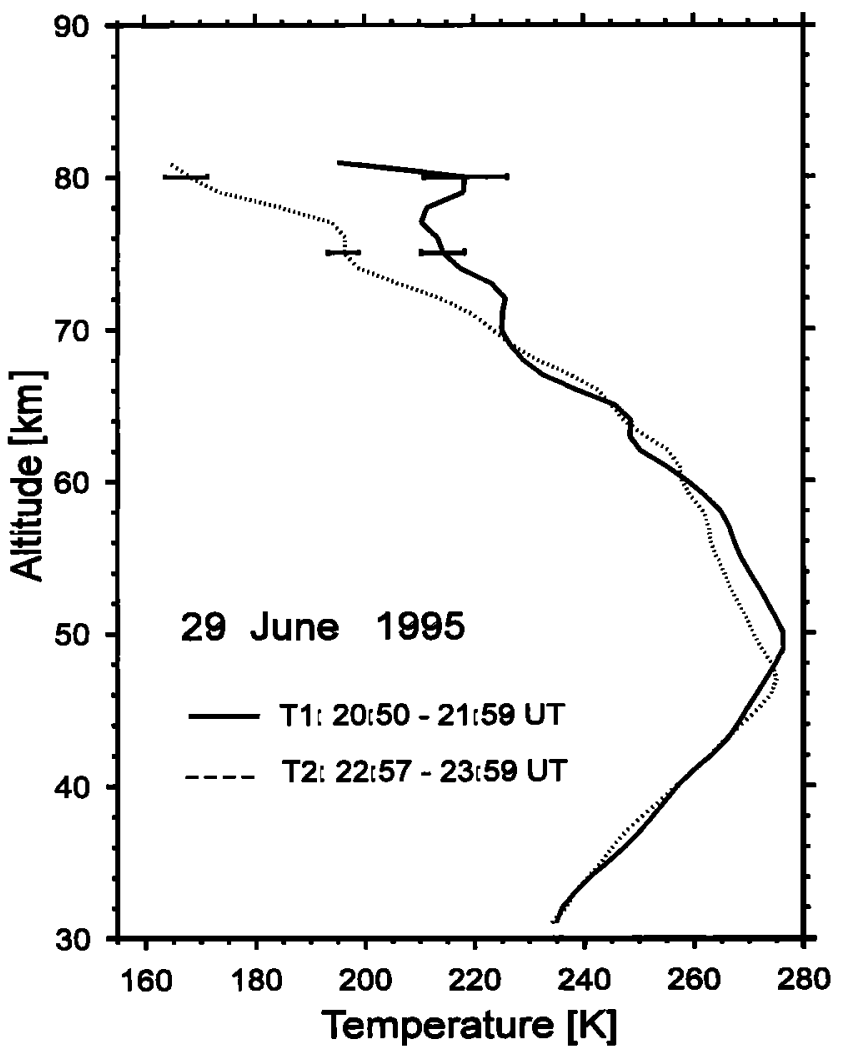

Figure 3. Temperature profiles with error bars for different time periods of the night of June 29th, 1995 obtained from integration of the lidar measured density profiles before the occurrence of the NLC event.

occurrence of the NLC layer. In Figure 2 the bars T1 and T2 mark the integration periods which were used to derive the two temperature profiles. Figure 3 depicts these temperature profiles and error bars at 74 and $80 \mathrm{~km}$. The integration period for each profile is about 1 hour. The solid line profile is centred at 21:24 UT and the dotted line profile at 23:27 UT. The profiles indicate (a) a cooling at $81 \mathrm{~km}$ of about $30 \mathrm{~K}$ over two hours immediately before the formation of NLC and (b) a tendency for decreasing temperatures towards the NLC altitudes.

During the nights of June 18th, and 29th noctilucent clouds were also visually observed at the northern horizon from the nearby weather station Arkona between 21:30-00:15 UT and 21:15-01:00 UT, respectively. The slowly varying observation angles of the NLCs were within the azimuth of $330^{\circ}$ to $60^{\circ}$ and $330^{\circ}$ to $70^{\circ}$ and the elevation within $3^{\circ}-13^{\circ}$ and $4^{\circ}-11^{\circ}$, respectively.

Figure 4 shows the variations of the zonal and meridional wind components at $83 \mathrm{~km}$ derived from the MF radar daytime measurements in the way described above. The bars in the lower part of the figure mark the NLC observation periods and the arrows the border between daytime measurements and interpolated wind values. The occurrence of NLCs was coupled with south-westwards directed wind values between $9-32 \mathrm{~m} / \mathrm{s}$.

\section{Discussion}

The observed three NLC events depicted in Figure 1 show a somewhat unexpected spread of their altitudes. Their mean altitude is $83.4 \mathrm{~km}$, which is close to the climatological mean NLC altitude of $82.9 \mathrm{~km}$ [Jesse, 1890; Gadsden and Schröder, 1989]. However, the layer at June $3 / 4$ is abnormal in the following ways: Its peak backscatter ratio $R=2$ is exceedingly small in comparison to other lidar-observed NLC layers and its peak altitude of $85.1 \mathrm{~km}$ is unusually high. Lübken et al. [1996] report about a similar lidar NLC observation with a peak backscatter ratio $R=5$ in an altitude of $87.5 \mathrm{~km}$ during the night of August $7 / 8,1993$. We suggest that these are cases of evolving NLCs which sediment downwards from the nucleation region (mesopause) while at the same time a few of the cloud particles grow to visible size. Consideration might be given to removing it from the altitude statistics because of its abnormality. The remaining two layers would have a mean altitude of $82.45 \mathrm{~km}$. The mean altitude of all NLC observations at mid-latitudes including two lidar measurements by Thomas et al. [1994] is $83.5 \mathrm{~km}$. Since 1989 a total number of 20 NLC events at polar latitudes (mean: $68.5^{\circ} \mathrm{N}$ ) were observed with lidar systems with a mean altitude of $82.8 \mathrm{~km}$. Both values are close to the climatological mean NLC altitude of $82.9 \mathrm{~km}$. It seems that the mean altitude of NLCs is independent of the latitude and the epoch.

The summer period of NLC events and, by implication, that of very low mesopause temperatures, appears to be shorter at mid-latitudes than that at high or polar latitudes. At mid-latitudes we observed NLC between June 3 and June 30, while Thomas et al. [1994] observed NLC at $52.4^{\circ} \mathrm{N}$ between June 21 and July 5. These dates cluster much closer about summer solstices than those of NLCs observed at high and polar latitudes. The latter period extends from the beginning of June until the middle of August.

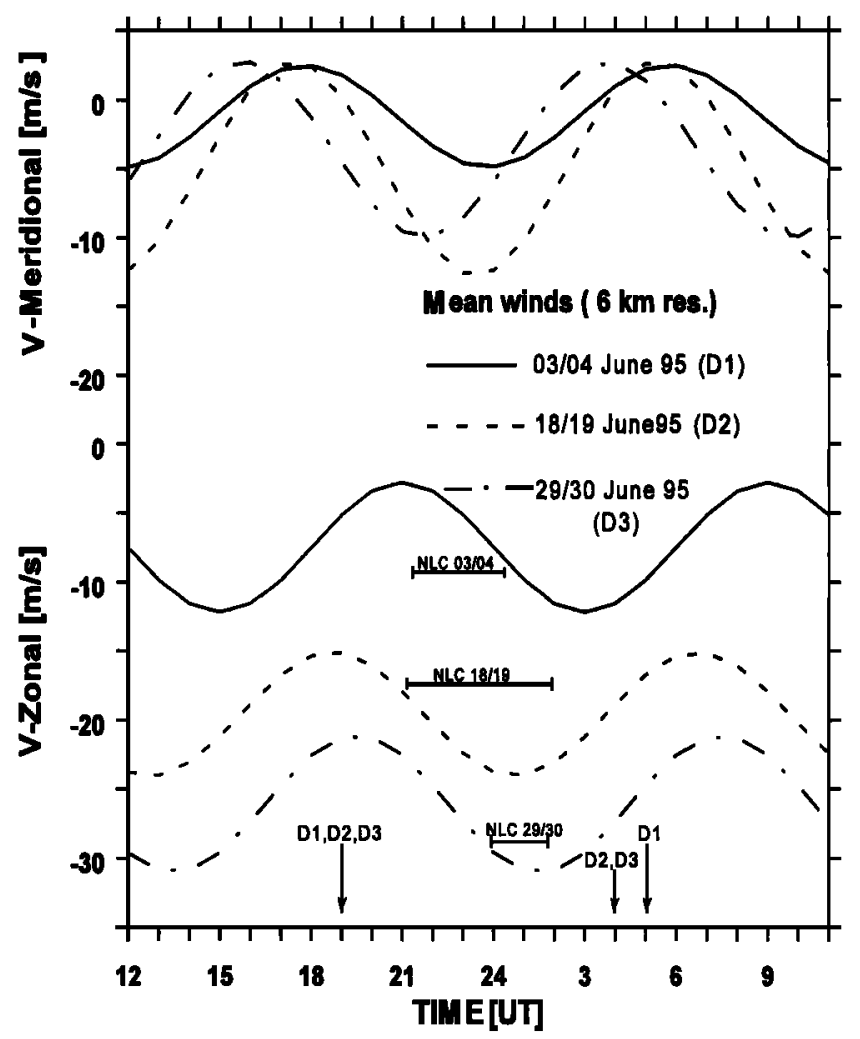

Figure 4. Meridional and zonal wind components measured by the Juliusruh MF radar during daytime and interpolated over the nights. The altitude of the analysis is $83 \mathrm{~km}$. The bars mark the periods of NLC observations and the arrows the borders between MF daytime measurements and interpolated nighttime values. 
In June of 1995 the weather station Arkona observed eight NLC events, all close to the northern horizon. During five periods of visual NLC sightings, the zenith-directed lidar was in operation, but did not observe a NLC layer. One visual NLC was obtained without simultaneous lidar measurements and one lidar observation of NLC was without visually observed NLC. During the occurrence of the three NLC events the interpolated MF radar wind was typically south-westwards directed with velocities between $9-32 \mathrm{~m} / \mathrm{s}$ as shown in Figure 4 which agrees with observations of Jesse [1890] and Nussbaumer et al. [1996]. There are some hints to a connection between the occurrence of NLC and a distinct behaviour in the amplitudes of the semidiurnal tides, which are not shown here. These investigations require a larger data set of simultaneous visual and lidar NLC observations combined with mesospheric wind measurements. We suggest that we have observed NLC clouds drifting through our measuring field of view. Particularly the course of the observation of the night of June 29th support this concept: at 21:15 UT a NLC is visually observed at the northern horizon, the MF radar derived south-westwards directed wind speed ranges between $10-26 \mathrm{~m} / \mathrm{s}$, the temperature at $80 \mathrm{~km}$ altitude is about $217 \mathrm{~K}, 2.5$ hours before the occurrence of the distinct NLC layer in the lidar signal. Within two hours the temperature in $80 \mathrm{~km}$ is cooled to about $168 \mathrm{~K}$ and a half hour later an increased backscatter appears in the lidar signal. Lübken et al. [1996] have shown that the lower edge of polar NLCs always falls close to the $150 \mathrm{~K}$ level. There is little reason to believe that this temperature is much different at mid-latitudes. Hence, observation of NLC at mid-latitudes indicates that even there in summer temperatures in the upper mesosphere fall at times below $150 \mathrm{~K}$. However, low temperatures may not be the only required ingredient for NLC events. Probably, the clouds are not formed at mid-latitudes, however, because this would need temperatures near $130 \mathrm{~K}$ for many hours. More likely, they are advected into the lidar field-of-view from higher latitudes. For this to happen, a required ingredient is a reasonably strong meridional (southward) wind just below the mesopause level.

Mid-latitude NLC observations offer interesting possibilities to study NLC-related phenomena. Some derive from the fact that, in contrast to polar latitudes, NLC can be observed in total darkness at mid-latitudes. This will permit to study the NLC particle density and size distribution with multi-color lidars, but without expensive spectral filtering for each color at the detector bench of the lidar. Further, even rather faint NLC can be observed, hopefully improving our knowledge about the life-cycle of NLC particles. The frequency and brightness of NLCs are strongly dependent on the thermal structure of the mesopause and the ambient water vapour mixing ratio. Hence, long-term NLC observations will support searches for trends in upper mesosphere temperatures, humidity, and/or dynamics.

Acknowledgments: The authors wish to thank J. Weiss and J. Mielich for the operation of the HERMES lidar at Juliusruh, D. Keuer for the operation of the MF radar, U. Feister for NLC data taken visually at the Arkona station of the German Weather Service (DWD) and A. Ebel and J. Roettger for fruttful discussions. The HERMES lidar was developed in collaboration between CNRS, CNES/ESA, and SESO.

\section{References}

Gadsden, M. and W. Schroder, Noctllucent Clouds, Springer-Verlag, Berlin, Heidelberg, New York 1989.

Hansen, G, M Serwazi, and U von Zahn, First detection of a noctilucent cloud by lidar, Geophys. Res Lett., 16, 1445-1448, 1989.

Jesse, O., Auffallende Abenderscheinungen am Himmel, Meteorol. Z., 2, 311-312, 1885

Jesse, $\mathbf{O}$., Untersuchungen uber die sogenannten leuchtenden Wolken, Sitzungsber. Preuss. Akad. Wiss., Phys.-Math. Kl. v. 3l. Juli, $1031-1041,1890$.

Keckhut, P., A. Hauchecorne, and M.L. Chanin, A critical review of the database acquired for the long-term surveillance of the middle atmosphere by the French Rayleigh lidars, J. Atmos. Ocean.Techn., 10, 850-867, 1993.

Langer, M., K.P. Müller, and K.H. Fricke, Rayleigh lidar detection of aerosol echoes from noctilucent cloud altitudes at Arctic circle, Geophys. Res. Lett., 22, 381-384, 1995.

Lübken, F.-J., K H. Fricke, and $\mathrm{M}$. Langer, Noctilucent clouds and the thermal structure near the Arctic mesopause in summer, J. Geophys. Res., 101, 9489-9508, 1996.

Nussbaumer, V., K.H. Fricke, M Langer, W. Singer, and U von Zahn, First simultaneous and common-volume observations of NLC and PMSE by lidar and radar, $J$ Geophys Res., I0I, August 27, 1996.

Singer, W., P. Hoffmann, D. Keuer, R. Schminder, and D. Kurschner, Wind in the middle atmosphere with partial reflection measurements during winter and spring in middle Europe, Adv. Space Res., 12, Vol. 10, 299-302, 1992

Thayer, J.P., N.B. Nielsen, and J. Jakobson, Noctilucent cloud observations over Greenland by a Rayleigh lıdar, Geophys. Res. Lett., 22, 2961-2964, 1995.

Thomas, L., A.K.P. Marsh, D.P Wareing, and M.A. Hassan, Lidar observations of ice crystals associated with noctilucent clouds at middle latitudes, Geophys. Res. Lett., 2I, 385-388, 1994.

von Zahn, U., and W. Meyer, Mesopause temperature in polar summer, J. Geophys. Res., 94, 14647-14651, 1989.

von Zahn, U., Temperature and altitude of polar mesopause in summer, in "COSPAR International Reference Atmosphere: 1986; Part 2: Middle Atmosphere Models", edited by D. Rees, J.J. Barnett, and K. Labitzke, Pergamon Press, p. 223-231, 1990.

G. von Cossart, P. Hoffmann, and U. von Zahn, Institut fuir Atmosphärenphysik an der Universität Rostock, Schloßstr 4-6, D-18225 Kühlungsborn, Germany. (e-mail: vcossart@iap-kborn.d400.de)

P. Keckhut and A. Hauchecorne, Service d'Aéronomie du CNRS, BP NN $^{\circ}$ 3, F-91371 Verrères le Buisson Cedex, France.

(Received July 16, 1996; accepted August 20, 1996.) 